\title{
The Cavendish tradition
}

\section{Professor Brian Pippard, present Director of the Cavendish Laboratory looks at its rôle in the forefront of physical research during the century of its existence.}

ON June 16, 1874, the doors of the Cavendish Laboratory were formally opened. A hundred years later, the last members of the Department of Physics left in those buildings are preparing to move to new quarters, still to be called the Cavendish Laboratory, on Madingley Road.

Cambridge was not the first university in the British Isles to encourage experimental physics, and if in its earliest years the Cavendish stood out from the rest, it was more because of its first two professors, Maxwell and Rayleigh, than for any notable difference in outlook. Only after this, with the inspired appointment of $\mathbf{J}$. J. Thomson at the age of 27 (not without some grumbling about mere boys being made professors), did the work begin to develop a special character. Of course the change was not sudden, but it is clearly revealed by comparing the publications in Rayleigh's day (before 1885) with those of 15 years later. Rayleigh at Cambridge is a different man from the gentleman scientist of Terling; he maintains the academic tradition of what we may call Natural Philosophy, undertaking with his students careful measurements to illustrate and guide mathematical reasoning, and to provide values of the constants of nature that pure reason alone cannot determine. By 1898 one has to search hard to find any trace of the earlier attitude; all is qualitative, the laborious search for patterns in phenomena beyond the reach of mathematical prediction. The names are revealing - Thomson, Rutherford, C. T. R. Wilson, Townsend, Zeleny-the roll-call of early investigators of electrical conduction in gases. Thomson had started to work in this field as soon as he was appointed, had discovered the electron in 1897, and had built up a small team ready for action when the discovery of $\mathrm{X}$ rays and radioactivity swept away the old world of physics and inaugurated the golden age of string and sealingwax.

Once more, let us remember that it was no sudden change; indeed, so far as the Cavendish was concerned these new effects principally gave new strength to the attack on gaseous conduction. But Rutherford in McGill was developing that technique which is now looked on as the epitome of the Cavendish tradition. How much was his own natural gift, and how much he picked up of what was congenial in J.J.'s approach, is hard to resolve; at all events, by the time he returned to the Cavendish in 1917, with his finest achievements behind him, he found there an outlook compatible with his own, and proceeded within the next few years to develop the laboratory to a world-commanding eminence.

This is the accepted version of the myth, though one wonders if it is seen in the same light in Manchester, where Schuster was succeeded by Rutherford, and he in turn by Bragg and then by Blackett. It was in Manchester that the atom was born and first disintegrated, yet to the world at large it is the Cavendish that stands for British physics in that period. This is not the only example of the compelling hold that Cambridge exerts on the emotions of its alumni, and it is a self-perpetuating process whereby in due course the old boys send their best students back to seek their fortunes. The reputation of the Cavendish rests partly on what its professors have done, but more securely on what its students and junior staff are doing. So many of the country's most talented students are attracted to Cambridge by its reputation, to be joined, those who stay for research, by so many equally promising graduates from elsewhere, that the head of department's task is to encourage and to criticise, not to dominate. The conventional picture of Rutherford as something of a one-man band is quite misleading. It ignores the contributions of Chadwick and many others too numerous to mention, who proceeded to chairs and spread the Cavendish gospel of nuclear physics to the wide world; it also ignores the presence of Appleton, Bernal, Kapitza and G. I. Taylor, some of those who benefited from Rutherford's support without being drawn into his orbit.

Nevertheless, in comparison with the laboratory we now know, Rutherford's was an archaic monolith that could not survive the expansion of physics after the second world war, and Bragg soon recognised that the time had passed when one man could oversee the whole research effort. Inevitably he was conscious of stepping into a giant's shoes, for it was many years before the Cavendish could free itself of the private feeling, and the world's expectation, that nuclear physics was the field it ought to cultivate above all others. But Bragg seized on the essential point that ideas are not the privilege of the leader but spring from the community of workers, and his decision to share responsibility among a number of virtually autonomous groups led to such successes as ultimately laid the ghost of the past. It was the seeds planted in the thirties by Kapitza, Bernal, Appleton, and Ratcliffe that grew in those years, so that by the end of Bragg's tenure Low Temperature Physics, Crystallography (especially what was to become Molecular Biology) and Radioastronomy were vying with Nuclear and Particle Physics to attract the best students. Devolution was complete; the laboratory was three times larger than at Rutherford's death, and its ability to contribute at the frontiers of research was now extended over a much broader field.

At the same time a certain weakness was becoming apparent. The experimental approach which we have traced to J. J. Thomson had developed into something of an antimathematical attitude; the followers of the prewar physicists, who had been amateurs in the best sense, were in danger of becoming merely amateurish in an increasingly professional world. And not only through disregard of essential theoretical techniques, but equally through nostalgia for the string and sealing-wax days when experiments were cheap and quick and, above all, for individual efforts. Thus, though some might have found a paradox in Mott's election to an experimental chair, and others welcomed it as a return to the ideals of Maxwell and Rayleigh, it is better seen as the recognition of the need to abandon parochial attitudes, such as the hope that physics will remain accessible to intuition and robust commonsense, with mathematics as an optional extra. Equally it was essential to realise that modern problems demanded modern equipment. Simplicity is for the man of genius; most of us have to do it the hard way. However much it may have wounded the pride of those who saw the Cavendish as something apart, it could only have been harmful to pretend that any single laboratory can go it alone nowadays. There will be local 
Lord Rutherford talking softly to J. A. Ratcliffe in the 1930s. traditions and national tendencies, but only as minor variants of an international style with, for example, British physics still leaning towards the experimental approach in contrast to the more mathematical tendency of the United States and Japan.

In keeping with this general trend many of the best contributions of the Cavendish in the last 20 years have been founded on technical innovations. The invention and exploitation of aperture synthesis for radiotelescopes, and the design and marketing of Sweepnik, the automatic scanner, are two very different examples of recent work in the old Cavendish style. Nor are there lacking descendants of the prewar amateurs, who eschew the beaten track and find more scope in opening up new lines, where observation and measurement get little guidance from established formalism. If we ask which type of work seems to be more highly regarded, the answer is rather disconcerting. For we smile at Rutherford's division of science into nuclear physics and stamp collecting, not recognising all round us the modern counterpart in the esteem we accord to mathematical analysis and, at best, the grudging respect for the accurate description of phenomena.

In looking to the future we could do worse than ponder for a moment the danger that always theatens physics of degenerating into scholasticism, of valuing the formal structure above all, especially if it can be disguised as ultimate truth. No one, of course, will dispute the mastery of those who have contributed to our deeper knowledge of the fundamental laws, and there is no physics laboratory but is richer for the presence of a leader in these studies. It is another matter, however, for students to be seen switching off their attention when the lecturer embarks on a discussion of observations that do not fit into any tidy pattern; and we are all too familiar with the way in which, given the choice, the brightest students choose theoretical physics, leaving the more experimental options for the less gifted. This is the legacy of a generation of professional research workers whose collective learning has established a standard which demands of all recruits such detailed formal knowledge as will leave them no time and, worse, no desire to tread paths where the signposts are few and uncertain.

This is one of the challenges which

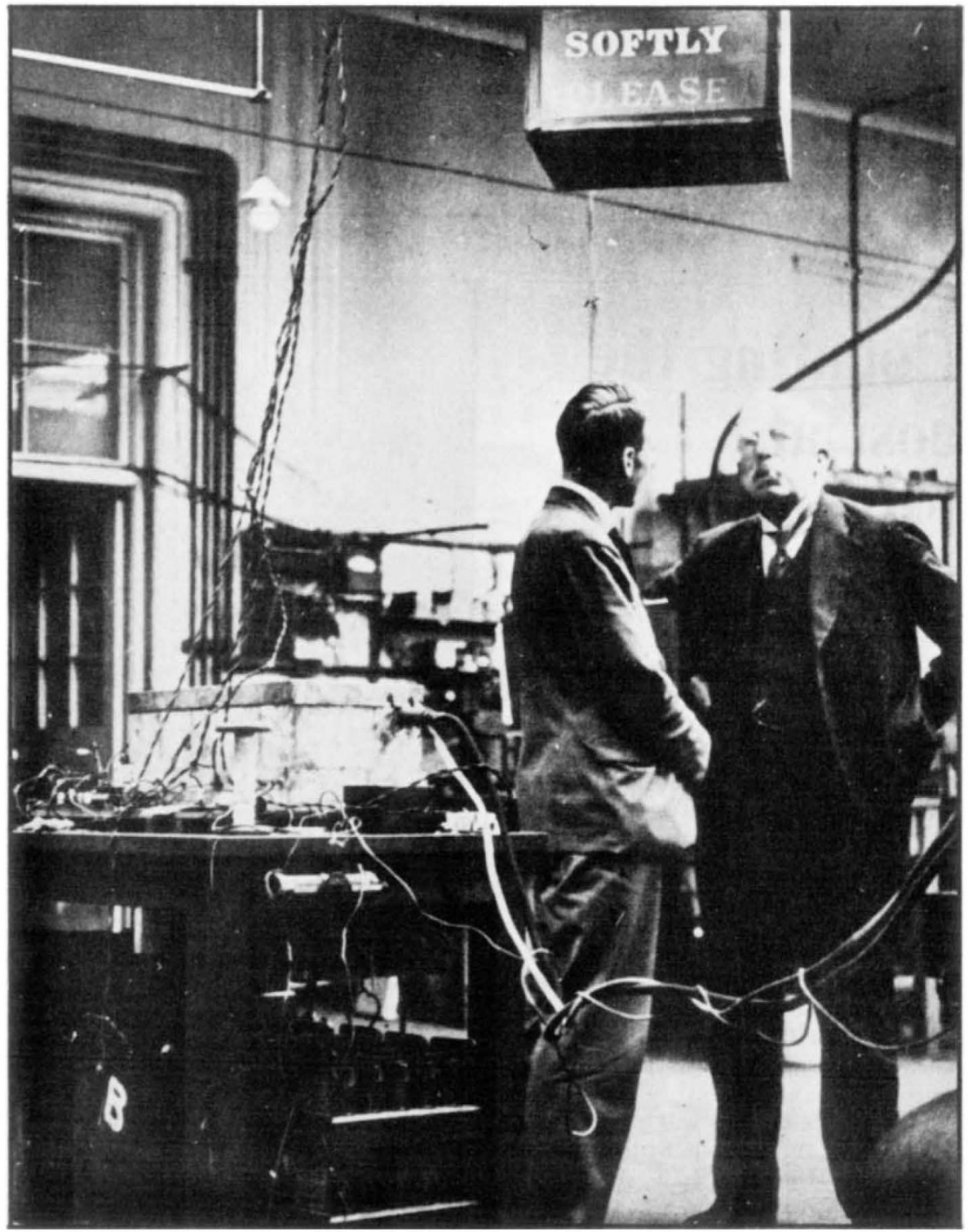

a laboratory like the Cavendish should attempt to meet. It has enough of a reputation to justify minor eccentricities of philosophy, and because of this, as well as the quality of its students, perhaps it has a greater responsibility than most to transit its version of the real nature of the subject. Its reputation never rested on knowing what everyone else had done, but on what its own members did, and how they inspired their students with the excitement of being a physicist. To carry on doing good research should not be too much of a problem, given that it is essentially a matter of catching and keeping as many as one can of the most ardent spirits, and providing the opportunity and encouragement for them to show what they are made of. But to carry this inspiration to the undergraduate level, where the need is greatest, is much harder than research--the urge is less, the praise fainter-and it is here that effort is really needed. To take a detached view, it could not be said to matter very much if most of the outstanding problems of physics were to remain unsolved. Yet it matters that we should continue to try to solve them, and discover new realms to explore, if only to renew in ourselves, and pass on to others, the assurance that physics is much more than a collection of laws whose application is a matter of knowledge and routine. For physics is, besides, a living craft of hand and mind which is transmitted more by example than by rote. Embodying as it does a technique essential to fight the material problems of the world, it must continue to be taught, and taught as a craft. There are countries whose universities teach that science is what the textbooks say, and reduce their students to intellectual sterility; and there are not lacking in this country influential men who would promote the same disaster here, believing innocently that academic research is an expensive luxury. The challenge of our times is not to assert, but to prove, that this is a dangerous illusion. If the Cavendish has a role to play, it is once more its traditional role-to be in the forefront of the battle. 